\title{
Ocean Governance and the Aporias of 'Accounting' and 'Accountability'
}

\author{
David Anthony Pittaway \\ ORCID iD: https://orcid.org/0000-0003-2342-0721
}

Andrea Hurst
ORCID iD: $\underline{\text { https://orcid.org/0000-0001-5707-2636 }}$

Joanna Botha

ORCID iD: https://orcid.org/0000-0003-0099-399X

Bernadette Snow

ORCID iD: https://orcid.org/0000-0002-1598-4511

\section{Abstract}

The Ocean Accounts Framework (OAF) developed by The Global Ocean Accounts Partnership for Sustainable Development, following a 'blue economy model', includes social and ecological value in its framework of accounts. It is hoped that this novel mode of accounting will improve ocean governance, which should contribute optimally (with the greatest possible justice) to ethical accountability, understood as sustainable human engagement with the ocean. As a work in progress, the OAF drafters acknowledge that more needs to be done to enhance its principles and particularly its social accounts. In this paper we aim for a philosophical critique of this laudable aim in the Kantian sense of an appraisal of its limits. Drawing primarily from Jacques Derrida's conception of aporias in his essay 'Force of Law' we argue that the limits (restrictions and 'chances') of the $\mathrm{OAF}$ are due to the aporetic complexity of key, interrelated fundamental commitments to: 'production and resources', 'inclusivity', 'optimal and just governance', and 'sustainable development'.

Keywords: Ocean Governance, Ocean Accounts Frameworks, complexity, aporia, ethical accountability, inclusivity, sustainable development. 


\section{Introduction}

Ocean governance (the process of creating and implementing ocean policy and applying ocean-governance instruments) is expected to contribute optimally (with the greatest possible justice) to sustainable human engagement with the ocean. It is assumed that optimal ocean governance can be measured in terms of how well policies and instruments promote the kind of oceanbased development that would ensure inclusivity, safety, security and sustainability in coastal communities. Further, it is assumed that the creation of ocean-governance policies and instruments would be optimal if informed by a shared technical framework for ocean accounting, in this case, the Ocean Accounts Framework being developed by The Global Ocean Accounts Partnership for Sustainable Development.

This Ocean Accounts Framework is designed to encompass analysis and research about economic, social and environmental ocean conditions (https://www.oceanaccounts.org/ 2019), to create a framework for measuring marine and coastal environments, the ocean's impact on people and how people change the ocean. Thus, The Global Ocean Accounts Partnership for Sustainable Development departs from more familiar approaches taken in accounting frameworks, which almost exclusively harness quantitative data and focus on production and industry. It aims to produce a novel kind of framework based on a blue economy model, which attempts to account for social and ecological value (both notoriously difficult to measure). A blue economy encompasses three pillars:

a) production and resources;

b) inclusivity - defined as sharing income and wealth equitably; and

c) sustainability - understood as protecting the ocean for future generations.

It should already be clear from these sparse definitions that an accounts framework based on a blue economy ventures into the complex, inadequately understood terrain of ethical accountability, of relationships between transformative environmental justice and human concerns for economic prosperity, social justice and well-being.

The Ocean Accounts Framework is a work in progress and the drafters, acknowledging that more needs to be done to enhance its principles 


\section{David Anthony Pittaway et al.}

and, particularly, its social accounts, called for multidisciplinary lines of investigation into its efficacy, which would, in turn, produce ideas for more optimal (or just) ocean governance. This is an exciting and laudable goal. In this paper, we aim to support it by adding a philosophical contribution. This will take the form of a critique, in the Kantian sense of an appraisal of its limits (Kant 1933). In a nutshell, we tie such limits (restrictions and 'chances') to the aporetic complexity of key, interrelated fundamental commitments to: 'production and resources', 'inclusivity', 'optimal and just governance', and 'sustainable development'.

More specifically, drawing primarily from Jacques Derrida, we propose that any Ocean Accounts Framework unavoidably and perpetually remains problematic due to the multiple forms of aporia that sit between the 'accounting' it relies on and the 'ethical accountability' it aims for. Derrida (1992:16) defines an aporia as 'something that does not allow passage. An aporia is a non-road'. As aporetic, he characterises justice (synonymously, 'ethical accountability') as 'the experience that we are not able to experience'. Yet, it seems imperative that we act justly and form optimally just policies and governance instruments. Thus, we find ourselves caught in the aporia created by the equal impossibility and necessity of achieving ethical accountability. However, we also take from Derrida the insistence that being caught within such an aporia does not give us an excuse to abdicate our responsibilities but motivates us to keep endlessly striving for optimal ocean governance.

The article aims to explain and justify our insistence that, due to the complex aporias of economy/aneconomy and law/ justice, the interdisciplinary team of Ocean Accounts Framework (OAF) developers and researchers are obliged constantly to re-think its basic principles, commitments and applications. Tiring as it is, and tiresome, this work never ends, and it produces uncertainty, frustration and anxiety. Yet, persistent re-thinking is essential to shift from a reliance on mere accounting towards the ideal of ethical accountability. Because this ideal is unreachable, it is in this perpetual effort, rather than a specific, fixed and measurable outcome that 'ethical accountability' resides. We conclude with some thoughts on what such rethinking means in practice.

In Part One, focusing on the economic pillar of the blue economy ('production and resources'), we lay the primary conceptual foundation of this article. We use Derrida's 'Aporias' (1993) to explain the connection and 
opposition between 'accounting' (as an economic concept using empirical, quantitative, calculable measures) and 'accountability' (an 'aneconomic' ethical concept, that incorporates concepts of chance, play, and violation). While we acknowledge and support the explicitly stated desire to shift the OAF towards ethical accountability by using 'more inclusive' measures that speak to a wider sense of sustainability, we problematise the overemphasis on the economic pillar of the blue economy ('production and resources') and, by extension, the 'economism' (Stiegler 2010:18) of the discourse. We believe that it would add value to acknowledge such economic/aneconomic aporias explicitly in an accounts framework, as well as in legislative or policymaking processes.

In Part Two, having supported the desire to shift the historically dominant focus on quantitative accounting towards the more-than-quantitative, we argue that the extreme complexity (indeed the impossibility) of the aim to achieve 'ethical accountability' should also be recognised. We rely on Derrida's 'Force of Law' (1992) to show that laws and policies, for which we can give a measured account, can never be fully ethically accountable. We show that an aim for optimal ocean governance responds, at best, to a persistent 'call for justice'. We argue that responding to the call for justice, while it is never-ending, is the only way to shift from mere accounting towards ethical accountability.

In Parts Three and Four we discuss 'inclusivity' and 'sustainability' as concepts representing, broadly, the ethical desire to bring the social and environmental pillars of the OAF into account. We support the explicit desire to contribute 'optimally' - with the greatest possible justice - to inclusive and sustainable human engagement with the ocean. Even so, we also insist upon its necessary impossibility due to the extreme complexity of these concepts.

In Part Five we consider the practical question of how to move within the aporia suggested by the equal necessity and impossibility of achieving ethical accountability. We use the economic/aneconomic dilemma to highlight the importance of incorporating aneconomic 'play' in project planning and implementation phases. This creates the feedback loops necessary to any project that aims to take account of irreducibly complex factors. We call for reflexive practices throughout the design and implementation phases of the OAF and in interactions with the governance sector. Further, we provide a brief glimpse of what a reflexive exercise might look like. We also identify a key challenge to the success of our contribution. 


\section{David Anthony Pittaway et al.}

We also turn to the argument made by Catalano (2019) - that it is important to acknowledge and learn from the failures of projects - to support our call for ongoing reflexive practices.

\section{Part One: Economic and Aneconomic Aporias and the Difference between Accounting and Accountability}

The terminological shift from 'accounting' to 'accounts' reflects an overall discursive shift from mere accounting to ethical accountability. This is evident in the stated goal of the Global Ocean Accounts Partnership to recognise 'environmental integrity for human existence' and to 'be inclusive of economic, social and environmental factors' (du Plessis \& Truter 2020:n.p.). The question frequently raised concerns the kinds of measures that best take account of more-than-quantitative value. Yet even the aim to include measures of social value and ecological value inevitably entangle designers of an accounts framework in multiple dilemmas (aporias), not least because what is socially or ecologically valuable to one person or group might not be to others.

Notably, however, if we reach aporias (irresolvable dilemmas or paradoxes) when attempting to take account of more-than-quantitative value, this is not a sign of error or mistaken thinking. Instead, it is a sign that we are on the right track because we are trying to do the impossible; namely, identify and precisely delineate aspects of irreducibly complex systems, which present endlessly moving targets. Derrida's work in 'Différance' (1982) and 'Aporias' (1993) on the concepts of 'economy', 'aneconomy', 'chance', 'play', and 'violation', summarised below, may be employed to assist in the difficult task of thinking about such complexities.

\section{The 'Economic' Mindset}

Economy is a word used narrowly and almost exclusively to denote a system of exchange and monetary interaction. Derrida uses the concept of 'the economic' (1982:19) more broadly to denote anything that is 'systematic' within a system; that is, orderly, precise, predictable, controlled, measurable, knowable, and so on. The economic, for example, implies an ordered, regulated, predictable movement of measurable investment and return, input and output, cause and effect. In the Derridean sense, too, whenever a person or group of people settle on specific meanings or precisely delineate objects, 
entities, processes, phenomena, or functions, they are acting according to an 'economic' mindset.

Traditional accounting frameworks, which usually focus on financial accounting, are good examples of narrowly economic attempts to measure value. Interestingly the term 'accounting framework' still dominates search results almost exclusively even when the relatively novel term 'accounts framework' is searched for. Accounting frameworks provide guidelines and protocols to arrive at numerical values that ground decision-making. Scientists, accountants, economists, and others who employ mainly quantitative methods of data collection, are also typically used to working with 'the economic' in a broader sense, including strict definitions and clearly delineated objects of study. The 'economic mindset' prefers to identify clear objects of study, define which terms and concepts are relevant in the study of the object, work with presumably universal quantitative models, and accordingly arrive at quantitative information and conclusions. Gross Domestic Product (GDP) is a good example of an exclusively quantitative measure of a country's wealth.

\section{The 'Aneconomic'Mindset}

Since the 'economic' mindset dominates ordinary discourse, 'aneconomy' is a neologism that few people would have encountered. Derrida (1982:19) uses the concept to refer to what is 'unsystematic' within a system of relations. The aneconomic is the unruly, unpredictable factor that threatens to disrupt and destabilise all that is systematic. Due to what is aneconomic in reality, broadly economic definitions or regulations perpetually risk being destabilised and revealed as limited, instantly outdated snapshots of unruly objects, entities, processes, phenomena, or functions. The aneconomic mindset recognises that as soon as economic structures come into being they are threatened with a degree of aneconomic 'violation'. This mindset not only prefers disruptive freedom, but shows a kind of 'passive aggression' through the con-tinuous deferral of economic definitions and regulations due to its minute attention to differences, deviations and exceptions.

An OAF opens itself up to the aneconomic mindset as early as in the naming stage of the process. A brief look at the words 'ocean' and 'accounts' quickly demonstrates this. Take the broadly economic attempt to define a particular ocean, for example, the Western Indian Ocean. This ocean exists in (economic) name only, because the water that constitutes the ocean, as well 


\section{David Anthony Pittaway et al.}

as much of the marine life that lives in it, move beyond the conceptual boundaries imposed by human beings. Even at the level of quantitative measurement, aneconomic slippage therefore occurs. At more qualitative levels, this slippage phenomenon increases in scale. For example, any attempt to measure (or define) the social value of the Western Indian Ocean would be thwarted by the unanswerable question: 'To whom is it valuable?' Different groups of human beings have different values; individuals within groups may not share the group's main values; and further, what is socially valuable can and does change over time. The word 'accounts', which is intended to replace 'accounting', similarly lends itself to aneconomic slippage. The question of what is meant by 'accounts' may quickly lead to various answers: for example, to take account of, to be accountable, and the accounts (stories and narratives) of others. Even more problematic than multivocality, meanings of 'the same' word slips. For example, to be accountable means substantially different things to different people.

\section{The Paradox of Ethical Accountability}

In relation to the 'economic' and 'aneconomic' mindsets, we remain caught up in a circle. The aneconomic mindset leads to an aporia (a dead end or moment of paralysis when there is an excess of meanings). Drafters of the OAF will understandably have to step away from aneconomic slippage at some stage. If anything is ever to be done or if one is ever to act, one must eventually conclude, make a decision, delineate the parameters of the framework. This makes it necessary to ignore open questions about social value, draw some economic boundaries, and just settle for definitions, guidelines, points, etc. In other words, designers of OAFs will understandably have to act in violation of the irreducible complexity they face. Nobody who wishes to use words, ideas, concepts, meanings, etc., can avoid this built-in injustice. However, the injustice is compounded if a broadly economically determined system is artificially kept too rigid, and if there is no tolerance for the kind of deferral, play and chance that risks violating and destabilising what has been decided. For example, the notion that GDP is 'the world's best system of economic statistics' (Anderson 2020:n.p.) for determining global value, has come under fire in recent decades since it has been identified as playing a causal role in the series of interlinked environmental problems that constitute the ecological crisis (Kovel 2006). So, rigidity suggests a different, but equally damaging aporia that reflects over-reliance on strictly quantitative 
measures of value to inform policy making.

Paradoxically, we get as close as we can to 'ethical accountability' only in the vacillation between two injustices; that is, between the opposing aneconomic and economic forms of violation that we wish to avoid equally. Derrida (1994:30) sums up how we may approach ethical accountability in his aphorism, 'give economy its chance'. 'Chance' here needs to be considered from at least two different angles. First, 'allow economy a chance to happen' and second, 'allow the aneconomic chance to happen to an economy' (Hurst 2008:86). The first sense of Derrida's statement is perhaps commonly encountered. For example, dictionaries and search engines are perpetually at hand for strict definitions of objects, entities, processes, or phenomena. Yet, any decision to settle on a specific definition, a specific set of criteria, a framework for measuring value, and so on, is a withdrawal from the dynamic and complex interplay of forces that are always shifting the targets, so to speak. As the one-liner attributed to Martin H. Fischer humourously states, a conclusion is the place where one got tired of thinking. Many a true word is spoken in jest! To be ethically accountable, however, one may not get tired of thinking, since 'despite our best efforts at resolving different kinds of [...] difficulties, such resolutions inevitably find themselves troubled in turn by further difficulties' (Hurst 2004:246).

In short, it is not sufficient for ethical accountability to remain entirely fixated on a chosen definition, criterion, frame or value. Instead, allowance must be made for slipping back into the aneconomic process of deferring and differing, which produces ever more conceptual material to explore. An ethical accounts framework must have a built-in tolerance for play; that is, an openness to slippage into the aneconomic possibilities that continue their interplay beyond the moment the accounts framework is finalised. Reflexive accounts framework evaluation processes should be built into planning and implementation protocols, allowing for feedback loops and updating with novel material. Suggestions on how to build reflexive evaluation processes into planning and implementation protocols are offered later.

\section{Part Two: The Aporias of Justice and the Transience of Optimal Governance Instruments}

Following Derrida's line of questioning in 'Force of Law' (1992:4), we must 


\section{David Anthony Pittaway et al.}

ask whether the incessant critical work we propose makes it possible to configure ocean-governance instruments that do justice, that achieve ethical accountability, in relation to the complex human/ocean encounter? The answer is both negative and affirmative. In a negative sense, this kind of work will not enable theorists (no matter how large a group and how multi-disciplinary) to produce an 'economic' account that will 'ensure, permit, or authorise' any single framework that will do justice to the 'aneconomic' complexity of our ethical accountability in relation to the complex human/ ocean encounter.

Derrida (1992:22) argues that the notion that there should be justice is a humanly created commitment, posed in defiance of an indifferent and sometimes unruly reality. As limited beings in a complex world, humans cannot bring Justice into being. All we can create is what we call a 'justice system', which is really a system of obligations and prescriptions made to enforce some or other limited definition of what justice means and entails. But, the basic principles that inform any justice system were selected without the comfort of an ultimate authority to guarantee their truth or value. Thus all justice systems (not only those that obviously and cynically serve dominant powers, but equally those that strive in 'good faith' to optimally embody Justice) are self-authorising. In Derrida's (1992:13) words: 'The very emergence of justice and law, the founding and justifying moment that institutes law implies a performative force, which is always an interpretative force'. This means that the hermeneutic performance by which the principles of justice are selected and defined (inclusivity, safety, security, sustainability, wealth generation, and equity, to name a privileged set of examples), immediately commits an injustice to other ways of framing things. Derrida (1992:6) speaks of this as perpetrating an 'originary violence'.

By extension, the basic principles and philosophical commitments that underpin the OAF have been selected without adequate authority behind them. But this is not a fault, flaw or error that can be remedied. Instead, it is a necessary (intrinsic) and insurmountable injustice associated with the creation of all such frameworks. Further, the injustice is compounded as soon as the framework is treated as the legitimate source of legislative authority by which to develop policies and enforce laws. Laws, as Derrida (1992:6) remarks, have to be forced upon people - 'whether this force be direct or indirect, physical or symbolic, exterior or interior, brutal or subtly discursive and hermeneutic, coercive or regulative, and so forth' - because no justice system could ever be perfectly and persistently fair to all citizens. What 
seems from one perspective to be an optimally just way of approaching things will immediately do an injustice to something excluded because the system cannot encompass everything; or something will enter the picture in a while (that is not yet imaginable as a factor to take account of). The very institution of a justice system must inevitably fail to do justice and it becomes very difficult to distinguish between what Derrida (1992:6) calls the 'force of law' (legitimate power, authority, public force) and the 'violence that one always deems unjust'. In short, when we try to act in a just way, we find ourselves tangled up in aporias.

Derrida (1992:22-29) explains the struggles involved in trying to act with justice as three versions of the economic/aneconomic aporia that confronts us with a dilemma between the calculable and the incalculable, or, to tie back to Part One, between our need to get things done through mere accounting and our desire for ethical accountability. The first aporia describes the paradox that to act with justice, we have to act both inside and outside a regulatory system of rules (Derrida 1992:22). To act justly a person must be free enough to take responsibility for thoughts, actions and decisions. But this plays out in opposing ways. To act justly, I need to be free from instinctual, impulsive and affective compulsions, and since justice only occurs as the function of a system of rules, I cannot be free or just if I am not working within a set of rules. So, I must have the power of calculation given by a system of rules, as well as the will to enter into calculations of, for example, fairness. And yet, equally, to act justly I need to be free of any existing set of rules that can guarantee a correct interpretation and correct action on that basis, because this would turn me into a mere calculating automaton, only capable of applying the given rules. To be free and responsible, I need to be able to disengage from the 'economic' accounting of a system of laws and suspend existing rules enough to critically reflect on them anew, and carefully choose which to follow. This situation remains aporetic since one has to work within the law for there to be justice at all, but justice is only possible insofar as the law is suspended.

The second aporia reiterates the paradox in terms of decisionmaking. To do justice, decisions must be made, and for this reason issues must be viewed as if they were decidable. It must be possible to make choices guided by careful 'learning' (interpretation, deliberation, reasoning and reflection) and it must be possible to 'justify' these choices, or at least explain and support them properly. And yet, making decisions based on 


\section{David Anthony Pittaway et al.}

calculations guided by pre-given rules or principles, is exactly what cannot be done if you want to do justice, since the guiding principles of any justice system remain undecidable. For example, invoking the universal 'ought' as a criterion for making a judgment violates the singularity, uniqueness, particularity of the case, and vice versa. Despite this impossibility of justly choosing a guiding principle for my decision, I am still obliged to decide. But whichever way I turn, my choice will not be just, because it necessarily and unavoidably commits an injustice in the very making.

The third aporia repeats the pattern in terms of waiting and knowledge. It is impossible to act justly without adequate knowledge of current conditions (environmental, cultural, socio-economic, political etc.), the histories of these, and an understanding of the values associated with them and so on. It is also impossible to do justice when conceptual uncertainty is caused by the widespread idiosyncratic use of seemingly familiar labels to name and describe core constructs, such as 'sustainable development' and social 'well-being'. The use of agreed upon meanings and terminology is undoubtedly critical for the success of a transdisciplinary project. However, infinite time is required by the justice that takes account of knowledge and strives for the supposedly right knowledge to make the decision. And, justice cannot wait for knowledge. To act justly, one must act in time. Justice cannot wait indefinitely for enough knowledge; for there is a point at which it will be too late, the time for justice will have passed.

The above aporias do not give us an excuse to abdicate before the question of ethical accountability. They do suggest, however, that we are bound constantly to negotiate the relation between the calculable and the incalculable. We are called, first to take account of an unlimited responsibility for learning; not just learning about, but also learning from one another. It is extremely important that, despite obstacles, this learning relentlessly remains interdisciplinary. No scholars are equipped with sufficient disciplinary expertise to do adequate justice to the specifics of thinking and rethinking complex concepts. We are also called to recognise that no oceangovernance instruments, even the most optimal for now, will remain optimal. By extension, the kind of critical work proposed in this article must form a relentless challenge to established laws, policies, and the frameworks that support them. In relation to our question of whether the incessant critical work we propose makes it possible in the end to configure ocean-governance instruments that do justice, that achieve ethical accountability, in relation to 
the complex human/ ocean encounter, the answer would be affirmative only in the sense that critical work keeps the laws, policies and frameworks open to adaptation. Ethical 'accountability' is, at its best, a caring, diligent, responsible answer to 'a call for justice' (Derrida 1992:16). This response takes the form of a persistent move away from the currently 'visible' injustices created by existing policies and laws and the will to change things to keep policies and laws optimal for their limited context and time-frame. This will be demonstrated in the discussion of 'inclusivity' and 'sustainability' in the sections to follow.

\section{Part Three: The Complexity of 'Inclusivity' as a Fundamental Principle}

Justice implies the element of universality that is intrinsic to the concept of 'inclusivity' (oceanaccounts.org 2020), which is a fundamental principle of the OAF. The OAF developers acknowledge that the framework may only move towards ethical accountability when there is a shift from a narrow focus on the economic pillar (production and resources), and greater effort is made to properly include other relevant dimensions (social and environmental) and their various stakeholders within the framework. Primary points for consideration taken from the Community of Practice (CoP) proposal documents are 'safety', 'security', 'equity' and 'sustainability'. These dimensions integrate an enormous network, including, for example, those who construct and research the frameworks; create, implement and enforce policies and governance instruments; represent community and non-human interests; are obligated by regulations and stand to lose or gain from them.

Further, if 'inclusivity' is an aim, it only seems just to establish a discourse for the OAF where all researchers and community stakeholders may discuss and decide things, according to a kind of universal 'language' that all are capable of understanding and interpreting. It is clear that, as Derrida puts it: 'The violence of an injustice has begun when all the members of a community do not share the same idiom throughout' (Derrida 1992:18). Thus, since we must speak a universal language that everyone can share in, the OAF aims to include the social and the ecological in the universal

1 The draft documents, while available online, are not for citation or reference, so see, for example, www.algoabayproject.com. 


\section{David Anthony Pittaway et al.}

language of, broadly, calculability or measurability (which departs from the narrow confines of mere quantification, or accounting).

Taking the argument further, it would also only be just to establish a discourse for the OAF where researchers and stakeholders may discuss and decide things, according to a 'language' in which all the stakeholders concerned are equally competent. In Derrida's words: 'It is unjust to judge someone who does not understand the language in which the law is inscribed or the judgment pronounced' (Derrida 1992:18). Implicitly this imposes an obligation on whoever is more competent to teach all participants 'how to read' the language and the laws of the discourse.

The pattern of the economic/aneconomic aporia described above is beginning to emerge. In order to be ethically accountable, the OAF must be inclusive, and to be inclusive, there is no getting away from the necessity to: establish a shared discourse; 'invite the outsiders in'; and ensure their competence to participate through 'education'. Yet, what seem to be necessities for the sake of avoiding the violations of exclusion, risk other kinds of violations.

Multiple problematics arise from the assumption that there can be a shareable 'language in general', understood to be 'a common currency'; that is, a language of calculability and measurability, into which all stakes can be translated without loss or remainder. The primary injustice in the name of justice takes the form of a power-relation. Derrida, with a hint of dry irony, encapsulates the dilemma as follows: 'It is more just to speak the language of the majority, especially when, through hospitality, it grants a foreigner the right to speak' (Derrida 1992:5). The irony, of course, is that the justice of 'inclusivity' (hospitality, or the invitation extended to the outsider) rests upon the prior injustice whereby the power-relation was originally set up that divides insiders from outsiders.

In the case of the OAF, the language of calculability is taken to be the legitimate universalisable discourse. Outsiders to this dominant discourse (many of those engaged in social studies, for example) have little choice but to surrender to the obligation to speak this language. Speaking as such an outsider to an English audience, Derrida (1992:4) notes: 'if, at least, I want to make myself understood, it is necessary that I speak your language'. By analogy, to be placed on the table at all, all participants in the OAF must speak the language of calculability because this is deemed by the law of the discourse to be the 'appropriate' and adequate way to pose problems and work out solutions (Derrida 1992:4-5). In relation to the social, for example, 
we find 'equity' translated in the CoP document, as the sharing of economic wealth. In a more general sense, 'inclusivity' implies that social studies researchers must be taught to understand the language of science; they must learn to make themselves scientific - they must become social scientists.

Further, as Derrida (1992:5) notes, 'I must respond to an invitation'. This speaks to the heart of the problem with the term 'inclusivity' - it implies something already established, something already there first, which is now able to extend a hospitable and caring (or should one read 'patronising'?) invitation to the outsiders it establishes - but 'terms and conditions apply'. Derrida (1992:5) again: 'I must be capable of understanding the contract and the conditions of the law - adopting, appropriating your language, which from that point ceases to be foreign to me'. Ironically, therefore, those outsiders who simply cannot re-make themselves to share the same idiom are left entirely out of account, as are those foreigners who do not wish to lose what is characteristically different about their own way of being. It is our contention that any effort to translate social and ecological stakes into the language of calculability (into calculable issues that might be resolvable through optimal policy and legislation) is to lose what is characteristic about social and ecological concepts - their infinite irresolvable complexity. Every concept, such as safety, security, equity, is a sheaf of interrelated and complex problematics for which there are no straightforward or final solutions.

In short, the violation of 'exclusion' must be thought of in tandem with the equal violation of 'inclusivity'. To approach the aim of 'ethical accountability' it is certainly necessary to bring together as equal partners the economic, social and ecological pillars of the OAF (notice that we have avoided the term 'include'). But this demands the dismantling of the powerrelation that privileges those disciplines that deal with what is easily calculable. Our contention here is that the OAF will not begin to approach 'ethical accountability' until it takes account of the proposition that the discourse of calculability (which supports, notably, an economic system of neoliberal capitalism) must be challenged and opened to radical disruption.

An example that supports our observation that some participants included in an accounts framework must suffer the injustice of having to learn the 'language' of calculability, is the problem of 'ocean grabbing' as discussed by Bennett et al. (2015:61-68). The concept refers to the unfair, non-inclusive distribution of marine resources to a select few in the ocean economy. This phenomenon is anathema in light of concepts such as 'ocean 
equity' (Österblom et al. 2020), as discernible in the following call (Österblom et al. 2020:2) for a far more inclusive dispensation in which humanand-ocean affairs unfold:

A sustainable ocean economy should protect human rights, improve human well-being, stimulate inclusion and gender equity, and prioritise recognition, diversity and equal access to resources to provide fair opportunities consistent with sustainable development. It should also address corruption and tax evasion, demand responsible and transparent business practices and create a shared economy that facilitates a fair redistribution of wealth and benefits. A sustainable ocean economy should be aware of environmental and social limits on growth and consider degrowth where appropriate.

In practice, the route taken in accounting frameworks has been, for example, to disaggregate data. This is illustrated in research conducted by Taylor et al. (2019:1407), who state that '[d]isaggregating data on sectors helps identify the value of specific sectors to countries. The most important sectors to a country can be measured by looking at the sector with the largest catch and highest value of catch'. A disaggregation process can be adopted to gain more precise data about specific aspects of an ocean economy that might have previously been lumped together in an aggregate and as a consequence been overlooked, unacknowledged or undermined in value. Thus, disaggregation in an OAF may be used to make visible previously excluded aspects in a bid to make the accounts framework more inclusive. However, a community of people awaiting, deserving, or demanding inclusion into the 'sustainable ocean economy' described above by Österblom et al. is still unlikely to derive recognition of value in the process of disaggregating (for example) fishery data. This is because value as such, even in disaggregated data, remains understood in terms of the dominant economic discourse. Such a community may derive value from a far more complex set of social and ecological factors such as overall well-being and a spiritual connection to life and place. It is in this light that the following call made by Foley et al. (2019:297) can be understood: 'contingent ecological and social forces that influence access should receive greater analytical attention, particularly as climate change transforms spatial relations between land-based interests and mobile marine species'. 


\section{Part Four: The Complexity of 'Sustainable Development' as a Fundamental Principle}

The OAF is designed to enhance reporting and assessment of a range of social, economic and environmental ocean-related conditions so as to align future decision-making with the achievement of sustainable development. 'Sustainable development' forms the third pillar of the OAF, with the drafters defining the latter as 'meeting the needs of the present without compromising the ability of future generations to meet their own needs' (UNESCO.org). This is the Brundtland formulation of the concept, which although contested, remains the most authoritative today, because it is accredited for creating and fostering core links in the causal economic-society-environmental chain (Lélé 1991).

Despite the emergence decades ago of 'sustainable development' as a global environmental imperative and ground norm, the concept is and remains unclear. For example, in 1992, Hardoy et al. identified over 80 definitions of sustainable development, most of which are competing and contradictory. Further, in the 1980s, Prezzey (in Baker 2016:35) recorded a 10-page list of the most commonly accepted definitions of the meaning of the term. To complicate matters further, sustainable development is also often framed as describing a tragic, yet complex paradox, not only because of its inability to bridge the environmental-human interface (Fey \& Lam 1999), but also because of the challenges associated with the measurement of the achievement of sustainable development.

Derrida (1992), as mentioned, conceptualised an aporia as a non-road - one that is a dead-end and does not allow passage - or, as Derrida (1992: 16) puts it, 'the experience that we are not able to experience'. Sustainable development is precisely this, because it is impossible to juxtapose and successfully advance both environmental care and the human development agenda simultaneously - hence, the oft expressed mismatch between what is demanded of the Earth and what the Earth is able to supply.

The dilemma begins with the meaning of 'sustainability'. This term, usually defined as 'being able to continue over a period of time', originated in the context of renewable resources, and has been regularly used as a catchphrase by the proponents of environmental care (Lélé 1991). Sustainability becomes extremely complex when coupled with terms such 'environmental', 'social', 'ecological', and 'growth', to name a few common 


\section{David Anthony Pittaway et al.}

combinations. Environmental sustainability is inherently ambiguous. It is uncertain whether we are referring to the sustainability of the environment's ecological systems and processes or to the imperative to address and overcome environmental problems if we are to maintain and develop our current social systems (Meadowcroft 1999). Similarly, social sustainability refers both to society's ability to maintain enough wealth and resources to reproduce itself and to the ethical purpose of achieving integrated living practices and reducing social conflict produced by economic activities. It is the interplay and tension between the environmental and social conditions necessary to achieve sustainability (let alone sustainable development) that will continue to challenge the OAF team, who must constantly reflect upon the OAF's guiding principles and commitments, even though this produces uncertainty and anxiety. However, as Derrida reminds us, this perpetual effort is not necessarily as precarious as it may seem, because being enmeshed within such an aporia motivates all concerned to keep striving to achieve the OAF's ideal of ethical accountability, inclusivity and just governance.

The aporia does not end with sustainability. It is sustainable development that underpins the OAF. Interpreted literally, sustainable development means 'development that can be continued - either indefinitely or for the implicit period of concern' (Lélé 1999, 608-609). This description, however, does not explain the meaning of development, which has also been debated for decades. Some theorists depict development through the lens of economic growth, whilst others (more astutely) describe development as encompassing the necessary social conditions to live a good life. Sen (2009), for example, argues that a full conception of development includes a wide range of dimensions of human well-being impacting on the capabilities of individuals to live valuable lives, which include political freedom, economic facilities, and social opportunities. But, notwithstanding this dissonance, it is clear that development encompasses a process of directed change, which must at the bare minimum include both the objectives of development and the means to achieve such development (Lélé 1999).

Sustainable development, when presented as a conceptual model of societal change, becomes multifaceted and paradoxical, not only because of the dissonance between the words 'sustainable' and 'development', but also because of the difficulties associated with connecting societal change, economic growth, human well-being and environmental protection. Whilst it may seem that we have not advanced beyond Tolba's denunciation in 1984 of 
sustainable development as 'an article of faith, a shibboleth; often used but little explained' (Lélé 1991:607), we are again reminded of Derrida's words: 'give economy its chance'. By choosing to ground the OAF within the realm of sustainability and the achievement of sustainable development, the drafters have delineated what they believe to be the most appropriate conceptual framework to enable the advancement of optimal ocean governance, despite the aporia of linguistic confusion.

Sustainable development comprises two key concepts (Baker 2016:20-21). The first of these is needs, specifically the essential needs of the world's poor, to which overriding priority should be given, versus the reduction in the wants (as opposed to the basic needs) of the world's industrialised rich. The second is limitations, to be imposed on technology and social organisation, so as to enhance the environment's ability to absorb the effects of human behaviour and to meet present and future needs. Yet, as mentioned, there is incongruity between what is demanded of the Earth and what the Earth is capable of developing - an eternal aporetic clash.

In sum, as discussed above, the meaning and significance of 'sustainable development' is not settled and the aporetic difficulties are aggravated in the OAF by the unfortunate coupling of sustainable development with accounting terminology such as 'accounts', 'assets', 'statistics', and 'flows to the economy'. The repeated use of such terms in the OAF are testimony to the difficulty of finding an appropriate negotiation of the relationship between human rights and environmental rights. Consider, for example, terminology such as 'the stocks and changes in stocks of environmental assets (natural capital) that provide benefits to people'. Further, the dignity of people who rely on the ocean is impaired if they are treated as a means to an end or counted as liabilities or assets within the broader ocean economy. The choice of nomenclature in the OAF (or, at the very least, the manner in which it is presented) should thus be revisited.

\section{Part Five: Recommendations and Challenges}

Three recommendations will be made. The first is entirely conceptual. While the word 'framework' will likely be impossible to amend in the OAF name, it may need to be conceptualised differently in order to resonate more with the economic-aneconomic dilemma already discussed, as well as with the notion of complexity that the dilemma is meant to illustrate. A simple computing 


\section{David Anthony Pittaway et al.}

analogy suffices for the purpose of reconceptualisation: framework as operating system. If a framework can be thought of as an operating system, then it can allow for updates to be made to the system on a regular basis. Downloads would be slippages into the aneconomic processes of deferring and differing, and the updating process would entail 'play' (as explored in Section Two) that ultimately updates the system with some novel information gleaned from swimming into aneconomic currents, so to speak. The framework would therefore be what is known in software development as a rolling release: downloads (play) retrieve the most up to date data and information; updates are made (to the framework), and the system accordingly functions slightly differently, but for the same (flexible) purposes that the system was originally built for.

The second suggestion is more practical, and calls for the development of a set of objectives that can be used to assist AF (accounts frameworks) designers and policy-makers to incorporate play into frameworks and their implementations. Here we draw from extant academic practice in the United Kingdom, where the academic bridge between high school and university is known as A Levels (previously named O Levels). There are various different A Level subjects, and each subject has a syllabus. Many syllabuses contain clearly listed Assessment Objectives (AOs). Here are the AOs for English Literature as they appear at the AQA webpage for English Literature:
AO1: Articulate informed, personal and creative responses to literary texts, using associated concepts and terminology, and coherent, accurate written expression.
AO2: Analyse ways in which meanings are shaped in literary texts. AO3: Demonstrate understanding of the significance and influence of the contexts in which literary texts are written and received.
AO4: Explore connections across literary texts.
AO5: Explore literary texts informed by different interpretations.

Note that the AOs do not specify or prescribe anything like an exact answer. Rather, they assist in describing broad categories, all of which should be referred to if students wish to create a well-rounded response to a question. We recommend that a similar approach be taken regularly in the design phases of an AF, and on an ongoing basis once policy has been implemented as per the AF, though a name-change from AOs to something like Assistance 
Guidelines (AG) would be necessary.

Assistance Guidelines for Reflexive Practice (AGRPs) could amount to the completion of basic paperwork (a table with several columns and rows) in group settings, in which different AGs are discussed and evaluated.

AG1, or column one, would provide a space for OAF content to be listed - for example, the decision to issue a specific number of fishing permits for a specific region of coast.

AG2, or column two, would be a space for the broadly economic dimension of the content, which in this instance may involve factors such as local residents who subsist off of fishing in the area, the area's observed ecological sensitivity, and other known factors.

AG3, or column three, would be a space for aneconomic or complexity factors - the issuing of a chosen number of fishing permits may have the impact of increasing the population of one species of fish, while decreasing its dominant source of food; and while permits may be conceptualised as effective methods of controlling fishing in an area, they may simply be ignored by local residents to the point that they are unenforceable.

AG4, or column four, would be a space in which systemic 'play' is addressed in order to answer the question, how can aneconomic factors be incorporated into the framework so that economic ones do not become too rigid? In the fishing permits scenario, research in the designated area would need to be ongoing, with (for example) annual changes to the number of fishing permits being made based on the research; and rather than simply enforcing permits, a dedicated team of stewards may be added to the programme for the purposes of communicating with local communities.

The fishing permit example is extremely limited and rudimentary; part of our recommendation is for further work on the AGs to be conducted. Once the AGRP protocol is developed, brief training or orientation sessions would need to occur so that designers of AFs are adequately prepared to think along the more lateral planes of the economy-aneconomy dilemma. This would be in keeping with approaches in A Levels, where the attendance of syllabus training days is common practice and indeed part of teachers' and lecturers' continuous professional development (CPD). During the AF design phases, brief check-in sessions involving all stakeholders would enhance the difficult process of thinking about, and planning for, complex issues. The same AGs that focus the check-in phases would be returned to once the final 


\section{David Anthony Pittaway et al.}

AF has been drafted, and the completed tables from previous sessions would be compared to the table at the end of the design process for review purposes.

It is particularly important that policy-makers and government officials are held to be accountable via the kinds reflexive practice that we have drawn attention to. Our recommendation for additional protocols is indeed made with the intention partly being to highlight the notion of accountability and foreground it as a priority of any OAF. By identifying challenging, yet workable, concepts to be brought in at various phases of OAFs design and implementation, we believe that we are taking steps to nurture and develop the kind of complexity thinking that is necessary to align and re-align OAFs with the reality of the moving targets that are in constant need of reconceptualisation. Policy-makers and government officials are, in theory at least, ultimately the people who ensure that an OAF will be implemented properly. Policy-makers and government officials would therefore also need to be part of a process in which complexity thinking is nurtured; this, however, is where the biggest challenge to our recommendations arises.

The challenge arises for two main reasons. The first, as explained in detail by Hathaway (2020:1), is that 'free market' policies have resulted in the creation of oligopolistic corporate economies'. Hathaway (2020:8) identifies deregulation in a global neoliberal context as central in a process that should really be named re-regulation: 'neoliberalism has involved reregulating while claiming deregulation. However, the nature of the reregulation has been to support corporate interests generally. Environmental, health, and consumer protection laws that impose costs on corporations have been opposed by politicians who seek to 'free the wealth creators'. In South Africa, unprecedented levels of corruption have been added to the political mix. In 2014 already, R. Manyaka and N. Nkuna pointed out (2014:1572) that 'although the South African public sector has a sound legislative framework and strategies for combating corruption, challenges such as the weaker application of the legislation and oversight mechanisms; insufficient political will; political deployments, and an absence of meritocratic systems provide opportunities for unethical, fraudulent and/ or corrupt activities to thrive'. Nothing has improved in this regard since 2014, with 'the plague of corruption, especially serious corruption at high levels in government' (Budhram \& Geldenhuys 2018:26) continuing unabated.

In light of the political factors just discussed, our third and final recommendation is that OAFs must take every opportunity to secure 
accountability at the political level. This can tie in with our second recommendation, which involves orientation sessions in which the aforementioned Assistance Guidelines are discussed in depth with policy-makers and government officials. As already stated, these sessions would be ongoing, which can allow them to act as proxies for regulatory processes that are more in tune with conservation priorities. OAFs could refer to such proxy regulatory processes as continuous professional development (CPD) for all stakeholders. Whether any success would be had in this regard remains to be seen, but in the absence of other options to secure accountability at the OAF implementation phase, a proxy regulatory process would at least be an attempt to initiate policy-makers and government officials into a way of thinking about complexity. Our position is that this proxy regulatory mechanism is one option if an Ocean Accounts Framework is to be interpreted partly as a framework towards accountability.

\section{Part Six: Learning from (and Anticipating) Failure}

Considering that our focus has largely been on using the terms discussed in Section Two as a way of addressing complexity, it is fitting that Allison Catalano et al. (2019:1) begin their article, titled 'Learning from published project failures in conservation', with the following remarks:

Conservation professionals operate in a highly dynamic, diverse, and complex world. Contexts change, often unexpectedly, and so it is essential that individuals, teams, and organizations integrate information and knowledge from a wide variety of sources and respond in ways that facilitate learning how to effectively navigate researchimplementation 'spaces' $[. .$.$] .$

Catalano et al. focus on various aspects of project failure, noting, as various other authors do (Catalano et al. 2019), that there is a 'dearth of published project failures' (2009:1), with researchers instead opting to 'document and recommend the replication of actions perceived to have delivered successful outcomes' (2019:2). Catalano et al. identify several factors that may discourage project stakeholders from formally acknowledging their failures, but more focus is given to providing insight into why projects fail. Their main findings in this regard are that inter- and intra- personal dynamics, as 


\section{David Anthony Pittaway et al.}

well as implementation actions, information flows, and funding, all played significant roles in project failures.

Drawing support from some other researchers, Catalano et al. state the following (2019:6): 'A positive attitude towards failure significantly improves the ability of individuals and their teams to learn from it. [...] [F]ew authors make explicit statements that recognize the value of failure, which, if more commonly found in published literature, might contribute to reducing the stigma surrounding it'. Furthermore, they make the following observations:

Disciplines that have developed explicit, structured processes for identification, analysis, correction and sharing of failure recognize that a prerequisite to coping effectively with it is recognizing and reframing negative emotions and countering the 'name, blame and shame' culture (except where clear violations have occurred) that may emerge from failure discussions [...]. Conservation organizations and donors should promote such a culture, using existing techniques common in other sectors such as: failure reporting amnesties; training on managing cognitive biases, conducting reflective debriefing sessions, and creating psychologically safe teams; and establishing systems to encourage and even reward failure reporting.

Catalano et al. have provided some indirect support for our general argument and some of our recommendations. Our general argument could be dramatically simplified: when any project participants stop deliberating and settle on the content of, for example, a framework, they have created a limited economic map of the territory they wish to traverse, and in so doing, they can be said to violate the territory by misrepresenting a dynamic, fluctuating, and complex process. The designers must enact such an economic violation and 'give economy its chance', but the moment they do so, they have lost sight of their targets. This dilemma could be rephrased: project stakeholders are doomed to failure - but 'failure' here should be read in a very loose manner.

This re-framing of the economy-aneconomy dilemma as one in which failure is inevitable should not be mistaken as cynical move. The move is made in order to align with Catalano et al.'s recommendation to foreground, 'and even reward', failure reporting and other types of interactive group sessions. We made use of the word 'violation' in earlier sections, but the word 
'failure' may serve a similar purpose. Our recommendation takes Catalano et al.'s recommendation considerably further, because our call for Assistance Guidelines for Reflexive Practice (AGRPs) to be employed during preimplementation phases of a project is indeed a way of preempting where violations or failures may occur (and as implied in Section Five, political factors cannot be omitted from the list of potential, even likely, failures). While our broadly post-structuralist approach foregrounds the inevitability of violation or failure by way of the economic-aneconomic dilemma, preemptive moves that arise out of AGRP sessions may add a helpful dynamic to a project's development and implementation phases.

The implementation phase of an OAF deserves a final word here, seeing as we have identified difficulties in this mainly political realm (Section Five). Catalano et al.'s identification of inter- and intra- personal dynamics, as well as implementation actions, as being among the primary causes of project failure (in the more specific sense of the word 'failure'), provide support for our call to try and foster accountability by way of taking AGRP training sessions beyond the development stages of an AF. Ongoing AGRP sessions would be attempts to nurture thinking that resonates with the complexity of the objects, entities, processes, and phenomena that projects such as OAFs are working with. AGRP training sessions could thus deliberately be designed to enhance inter- and intra- personal dynamics in the spirit of supporting and assisting policy-makers and government officials to be accountable. Failures along the way are (in the broadly post-structuralist sense) inevitable, but Catalano et al. support the call to learn from failure. We have gone a step further to suggest that, to some extent, project participants can acknowledge and foreground failure in the looser sense of the word.

\section{Concluding Remarks: The Way Forward}

We have emphasised aspects of a dilemma in two primary ways. First, we have emphasised that designers of frameworks, as well as anyone else who must define their terms and make decisions, face the dilemma of working with economic maps rather than the irreducibly complex aneconomic forces that instantly render all maps out-dated the moment they are drawn. Second, we have emphasised the importance of acknowledging the economicaneconomic dilemma. An Ocean Accounts Framework must be drafted; designers must choose to draw territory lines and specify definitions, as well 


\section{David Anthony Pittaway et al.}

as settle on specific points that constitute challenging categories of qualitative value. At the same time, designers can apply reflexive tools throughout the design and implementation phases of their framework, routinely interrogating their decisions by deconstructing them as necessary economic violations. Routine interrogation would allow for updated material to be accessed, thus allowing 'the aneconomic chance to happen to an economy'. The appropriate analogy for a given framework would therefore be an operating system that periodically updates itself by retrieving novel data and information via downloads. Slippage towards the aneconomic - i.e. 'play' - would be the analogue for a download.

While the inclusion of reflexive and interrogative processes may intimidate framework designers of the more quantitative persuasions, and while unorthodox post-structuralist ideas may take some time to fit into any framework protocol, the recommendations made in Section Six are not outlandish. AF designers would have to engage in 'play' as discussed in Section Two; and while some participants would undoubtedly resist doing so, such experimental gestures do resonate with the spirit of complexity that is gradually being taken seriously in Academia and in other arenas too. One arena that is unlikely to engage in 'play', or embrace the spirit of complexity, is the South African political sector, which appears to be bent on pursuing narrowly economic, and highly problematic, trajectories in the pursuit of financial gain for powerful individuals. If AF designers could incorporate ideas similar to the ones put forward in this paper into their frameworks, they will have to strategise about how to get the ideas incorporated at the political level, which is where AFs are ultimately implemented. This would be an attempt to foster political accountability, which may be achieved via proxy regulatory processes packaged as continuous professional development training sessions in which Assistance Guidelines for Reflexive Practice are developed and promoted.

\section{Acknowledgements:}

This research was funded by the South African Research Chairs Initiative through the South African National Department of Science and Innovation/ National Research Foundation, by a Community of Practice grant in Ocean Accounts Framework (UID: 125455). The opinions expressed in this publication are not necessarily those of the funding bodies. 
This work is based on the research supported by the National Research Foundation of South Africa (Grant Number 99188, SARChI Chair in Identities and Social Cohesion in Africa, Nelson Mandela University). Opinions, findings, conclusions and recommendations expressed in this work are those of the author's alone and the NRF accepts no liability whatsoever in this regard.

David Anthony Pittaway acknowledges the financial support received (while co-researching and co-writing this paper as a post-doctoral fellow) from the Institute for Coastal and Marine Research (CMR) at the Nelson Mandela University (NMU). All views and opinions expressed in this article belong to the authors, and do not necessarily reflect any official position or policy of the CMR or NMU.

\section{References}

Algoabayproject.com n.d. Community of Practice: Ocean Accounts Framework.

https://www.algoabayproject.com/ocean-accounts-framework

(Accessed 16 April 2021.)

Anderson, L. n.d. Gross Domestic Product. The (Online) Library of Economics and Liberty.

www.econlib.org/library/Enc1/GrossDomesticProduct.html

(Accessed 16 April 2021.)

Baker, S. 2016. Sustainable Development. $2^{\text {nd }}$ Edition. London and New York: Routledge.

Bennett, N. \& H. Govan \& T. Satterfield 2015. Ocean Grabbing. Marine Policy 57: 61 - 68. Available at:

https://www.sciencedirect.com/science/article/pii/S0308597X15000755

(accessed 16 April 2021.) https://doi.org/10.1016/j.marpol.2015.03.026

Budhram, T. \& N. Geldenhuys 2018. Corruption in South Africa: The Demise of a Nation? New and Improved Strategies to Combat Corruption. South African Journal of Criminal Justice 31,1: 26 - 57. Available at:

https://journals.co.za/doi/10.10520/EJC-107bf8bd84

(Accessed 16 April 2021.)

Catalano, A. \& J. Lyons-White \& M. Mills \& A. Knight 2019. Learning from Published Project Failures in Conservation. Biological Conservation 
David Anthony Pittaway et al.

238: 1 - 10. Available at:

www.sciencedirect.com/science/article/abs/pii/S0006320719307451

(Accessed 16 April 2021.) https://doi.org/10.1016/j.biocon.2019.108223

Derrida, J. 1982. Différance. In Margins of Philosophy. Bass, A. (trans.).

New York: Harvester.

Derrida, J. 1992. Force of Law: The 'Mystical Foundation of Authority'.

In Deconstruction and the Possibility of Justice. Cornell, D. \& M.

Rosenfeld \& D. Carlson. (eds.): New York, London: Routledge.

Derrida, J. 1993. Aporias. Du Toit, T. (trans.). California: Stanford University Press.

Derrida, J. 1994. Given Time: 1. Counterfeit Money. Kamuf, P. (trans.). Chica go: University of Chicago Press.

Du Plessis, N. \& H. Truter. 2020. Valuing our Oceans - A Novel Ocean Accounts Framework for South Africa. Available at:

https://enews.saeon.ac.za/issue-03-2020/valuing-our-oceans-a-novelocean-accounts-framework-for-south-africa/

(Accessed 16 April 2021.)

Fey, W. \& A. Lam. 1999. The Ecocosm Paradox. Available at:

www.eolss.net/Sample-Chapters/C15/E6-63-06-02.pdf

(Accessed 16 April 2021.)

Foley, P. \& C. Mather. 2019. Ocean Grabbing, Terraqueous Territoriality and

Social Development. Territory, Politics, Governance 7,3: 297 - 315.

Available at:

https://www.tandfonline.com/doi/full/10.1080/21622671.2018.1442245

(Accessed 16 April 2021.)

https://doi.org/10.1080/21622671.2018.1442245

Hardoy, J. \& D. Mitlin \& D. Satterthwaite. 1992. Environmental Problems in

Third World Cities. UK: EarthScan.

Hathaway, T. 2020. Neoliberalism as Corporate Power. Competition and

Change 24,3-4: 1 -23. Available at:

https://journals.sagepub.com/doi/full/10.1177/1024529420910382

(Accessed 16 April 2021.) https://doi.org/10.1177/1024529420910382

Hurst, A. 2004. Derrida's Quasi-transcendental Thinking. South African

Journal of Philosophy 23,3: 244 - 266. Available at:

https://www.tandfonline.com/doi/abs/10.4314/sajpem.v23i3.31396

(Accessed 16 April 2021.) https://doi.org/10.4314/sajpem.v23i3.31396

Hurst, A. 2008. Derrida Vis-à-vis Lacan: Interweaving Deconstruction and 
Ocean Governance and the Aporias of 'Accounting' and 'Accountability'

Psychoanalysis. USA: Fordham University Press.

https://doi.org/10.5422/fso/9780823228744.001.0001

Kant, I. 1933. Critique of Pure Reason. Kemp Smith, N. (trans.). London: Macmillan.

Kovel, J. 2006. The Enemy of Nature: The End of Capitalism or the End of the World? $2^{\text {nd }}$ Edition. London and New York: Zed Books. https://doi.org/10.5040/9781350251007

Lélé, S. 1991. Sustainable Development: A Critical Review. World Development 19,6: 607 - 621. Available at:

https://www.sciencedirect.com/science/article/abs/pii/

0305750X9190197P (Accessed 16 April 2021.)

https://doi.org/10.1016/0305-750X(91)90197-P

Manyaka, R. \& N. Nkuna. 2014. The Phenomenon of Corruption in the South African Public Sector: Challenges and Opportunities. Mediterranean Journal of Social Sciences 5,27: 1572 - 1580. Available at:

https://www.richtmann.org/journal/index.php/mjss/article/view/5241

(Accessed 16 April 2021.)

Meadowcroft, J. 1999. The Politics of Sustainable Development: Emergent Arenas and Challenges for Political Science. International Political Science Review 20,2: 219 - 237. Available at:

www.journals.sagepub.com/doi/10.1177/0192512199202006

(Accessed 16 April 2021.) https://doi.org/10.1177/0192512199202006

OceanAccounts.org 2019. Technical Guidance on Ocean Accounting. Available at: https://www.oceanaccounts.org/technical-guidance-onocean-accounting-2/ (Accessed 16 April 2021.)

Österblom, H. \& C. Wabnitz \& D. Tladi. 2020. Towards Ocean Equity. Washington, DC:

World Resources Institute. Available at:

www.oceanpanel.org/how-distribute-benefits-ocean-equitably

(Accessed 17 April 2021.)

Sen, A. 2009. The Idea of Justice. Cambridge, Massachusetts: The Belknap Press of Harvard University Press.

Stiegler, B. 2010. For a New Critique of Political Economy. Ross, D. (trans.). Cambridge: Polity Press.

Taylor, S. \& M. Roberts \& B. Milligan \& R. Ncwadi 2019. Measurement and Implications of Marine Food Security in the Western Indian Ocean: An Impending Crisis? Food Security 11,6: 1395 - 1415. Available at: 
David Anthony Pittaway et al.

https://link.springer.com/article/10.1007/s12571-019-00971-6

(Accessed 17 April 2021.)

https://doi.org/10.1007/s12571-019-00971-6

UNESCO.org n.d. Sustainable Development. Available at:

https://en.unesco.org/themes/education-sustainable-development/what-

is-

esd/sd\#: :text=Sustainable\%20development\%20is\%20the\%20overarchi ng,to\%20meet\%20their\%20own\%20needs.\%E2\%80\%9D

(Accessed 16 April 2021.)

Dr. David Anthony Pittaway Postdoctoral Researcher

Philosophy

Nelson Mandela University Port Elizabeth pittaway@gmail.com

Professor Andrea Hurst Philosophy

Nelson Mandela University Port Elizabeth Andrea.Hurst@mandela.ac.za

Professor Joanna Botha Public Law

Nelson Mandela University Port Elizabeth Joanna.Botha@mandela.ac.za

Dr. Bernadette Snow One Ocean Hub Strathclyde University Glasgow Bernadette.snow@strath.ac.uk 